\title{
The intersection of aging, longevity pathways, and learning and memory in $C$. elegans
}

\section{Geneva M. Stein and Coleen T. Murphy*}

Glenn Laboratories for Aging Research, Department of Molecular Biology, Lewis-Sigler Institute for Integrative Genomics, Princeton University, Princeton, NJ, USA

Edited by:

Thomas Flatt, University of Veterinary Medicine Vienna, Austria

\section{Reviewed by:}

Arjumand Ghazi, University of

Pittsburgh School of Medicine, USA

Yun Zhang, Harvard University, USA

*Correspondence:

Coleen T. Murphy, Glenn Laboratories

for Aging Research, Department of

Molecular Biology, Lewis-Sigler

Institute for Integrative Genomics,

Princeton University, 148 Carl Icahn

Laboratory, Washington Road,

Princeton, NJ 08544, USA.

e-mail: ctmurphy@princeton.edu
Our understanding of the molecular and genetic regulation of aging and longevity has been greatly augmented through studies using the small model system, $C$. elegans. It is important to test whether mutations that result in a longer life span also extend the health span of the organism, rather than simply prolonging an aged state. C. elegans can learn and remember both associated and non-associated stimuli, and many of these learning and memory paradigms are subject to regulation by longevity pathways. One of the more distressing results of aging is cognitive decline, and while no gross physical defects in C. elegans sensory neurons have been identified, the organism does lose the ability to perform both simple and complex learned behaviors with age. Here we review what is known about the effects of longevity pathways and the decline of these complex learned behaviors with age, and we highlight outstanding questions in the field.

Keywords: aging, C. elegans, insulin signaling, memory, learning, longevity, behavior, neurons

\section{INTRODUCTION}

Human learning and memory decline with age. Understanding the genetic basis of this decline could lead to preventative treatments and therapies. C. elegans is an ideal model organism to identify genetic pathways that regulate both aging and cognitive decline, with its established use as a model for aging (Klass, 1977; Friedman and Johnson, 1988; Hosono et al., 1989; Kenyon et al., 1993), synapse formation and function (Sulston and Horvitz, 1977; Lewis et al., 1980; Sulston et al., 1983; Rand and Russell, 1984; White et al., 1986), and neuron-mediated behaviors (Ward, 1973; Dusenbery, 1974; Chalfie and Sulston, 1981; Avery and Horvitz, 1989; Bargmann and Horvitz, 1991).

C. elegans is a small (1 mm long) transparent nematode found worldwide in rotting vegetable matter (Brenner, 1974; Felix and Braendle, 2010). The cell lineages of all 959 somatic cells in the adult hermaphrodite have been mapped (Sulston and Horvitz, 1977; Kimble and Hirsh, 1979), as has the position and connectivity of the 302 neurons (White et al., 1986; Varshney et al., 2011). Additionally, more than $80 \%$ of C. elegans genes have a human ortholog (Lai et al., 2000). C. elegans is a well-established model for studying the genetic basis of aging. While the normal lifespan of $C$. elegans is 23 weeks, many lifespan-extending mutants have been identified. Insulin/IGF-1 signaling (IIS) and caloric restriction (CR) regulate aging in C. elegans, and are conserved in higher organisms (McCay and Crowell, 1934; Kenyon et al., 1993; Lakowski and Hekimi, 1998; Bluher et al., 2003; Wood et al., 2004; Suh et al., 2008; Anderson et al., 2009). Because of its simple nervous system, C. elegans is also a model for synapse function (reviewed in Richmond, 2007), neuron-mediated behaviors (reviewed in Hobert, 2003), and learning and memory (reviewed in Ardiel and Rankin, 2010). Here we review age-related changes in learning and memory and their regulation by insulin signaling, mitochondrial metabolism, and CR.

\section{ELEGANS LONGEVITY PATHWAYS INSULIN/IGF-1 SIGNALING}

Reduction of insulin signaling was first found to increase longevity in C. elegans (Kenyon et al., 1993), and this evolutionarily conserved pathway has also been shown to influence lifespan in flies, mice, and humans (Clancy et al., 2001; Tatar et al., 2001; Bluher et al., 2003; Suh et al., 2008). In worms, there is a single insulin receptor tyrosine kinase homolog, daf-2 (Kimura et al., 1997), which was originally discovered for its role in the formation of dauers (Riddle et al., 1981), an alternative developmental stage that C. elegans can enter in order to survive in harsh environments. daf-2 Loss-of-function mutants have twice the lifespan of wild-type worms (Kenyon et al., 1993). The lifespan extension observed in daf-2 worms is dependent on the forkhead box $\mathrm{O}$ (FOXO) protein transcription factor, DAF-16 (Kenyon et al., 1993; Ogg et al., 1997; Lin et al., 2001). When the insulin-like growth factor 1 receptor (IGFR) DAF-2 is activated, a PI3 kinase cascade is triggered that ultimately phosphorylates DAF-16/FOXO and sequesters the transcription factor in the cytoplasm (Lin et al., 2001). age-1, The first gene discovered to regulate longevity in $C$. elegans (Friedman and Johnson, 1988), encodes an ortholog of the p110 catalytic subunit of Class IA phosphoinositide 3-kinase (PI3K) (Morris et al., 1996). The longevity of age-1 mutants is dependent on daf-16 (Dorman et al., 1995), and genetic analysis showed that AGE-1/PI3K functions downstream of DAF-2/IGFR and upstream of the AKT-2/AKT-1 and PDK-1 kinases and DAF16/FOXO transcription factor (Paradis and Ruvkun, 1998; Paradis et al., 1999). In the absence of insulin signaling, DAF-16/FOXO is localized to the nucleus, where it regulates a host of genes that promote longevity and stress resistance. The proteins involved in IIS and many of the downstream targets of DAF-16/FOXO that contribute to the phenotypic outputs of insulin signaling (Murphy et al., 2003) have been identified and characterized. 
C. elegans encodes approximately 40 insulin-like peptides that can act as either DAF-2 agonists and antagonists (Pierce et al., 2001; Li et al., 2003; Murphy et al., 2003, 2007). Most of the insulin-like peptides are expressed in the neurons, though a few are expressed in the intestine as well (Pierce et al., 2001; Li et al., 2003; Murphy et al., 2007). Pierce et al. (2001) identified INS-1 as the closest homolog of human insulin, and found that overexpression of ins-1 or human insulin antagonizes daf- 2 signaling, moderately increasing lifespan and enhancing dauer arrest. Loss of ins-1 did not influence lifespan or dauer entry, probably due to functional redundancy among insulin-like peptides (Pierce et al., 2001). Along with influencing dauer arrest and longevity, ins- 1 has recently been implicated in regulation of many neuron-specific sensory behaviors, such as neuropeptide feedback, serotonergic signaling, and starvation-associated aversion learning (Kodama et al., 2006; Tomioka et al., 2006; Chalasani et al., 2010; Lin et al., 2010; Harris et al., 2011).

\section{MITOCHONDRIAL METABOLISM}

Through metabolic processes, mitochondria produce the most reactive oxygen species (ROS) in a majority of eukaryotic cells (Kowaltowski et al., 2009). Excessive ROS react with proteins, DNA, RNA, and lipids, causing oxidative damage (Richter et al., 1988; Grune et al., 1997; Crawford et al., 1998). (Details of the specific mechanism of ROS production are reviewed in Kowaltowski et al., 2009). Oxidative damage caused by ROS is thought to contribute to aging, though the extent and mechanism of its action is not yet known. Mutations in the C. elegans clk-1 gene, which encodes a hydroxylase in the electron transport chain that is required for ubiquinone biosynthesis (Miyadera et al., 2001), result in extended lifespan (Wong et al., 1995). isp-1 Encodes the iron sulfate protein of the electron transport chain, and mutation of isp-1 decreases metabolic respiration and increases lifespan (Feng et al., 2001). Mutations in two additional genes in the electron transport chain, mev-1, which encodes a cytochrome $b$ homolog, and gas-1, which encodes the major $49 \mathrm{kDa}$ iron protein subunit of complex 1, show reduced resistance to ROS and shortened lifespan (Adachi et al., 1998; Ishii et al., 1998; Kayser et al., 2001, 2004). RNAi screens have identified many mitochondrial genes that regulate lifespan in a daf-16 and daf-2-independent manner (Dillin et al., 2002; Lee et al., 2003). While the exact mechanisms by which metabolic mutations influence longevity remain largely unknown, lower levels of ROS-damaged proteins in $c l k-1$ mutants and higher levels in gas-1 mutants support the theory that damage caused by ROS contributes to functional decline during aging (Kayser et al., 2004).

\section{CALORIC RESTRICTION}

Restricting caloric intake to $60-70 \%$ of normal levels was first shown to extend rat lifespan by McCay et al. (1935) and has since been demonstrated in many organisms, from yeast to primates (McCay et al., 1935; Weindruch, 1996; Lin et al., 2000). Many methods of calorically restricting wild-type C. elegans result in a lengthened lifespan, including growing worms in or on diluted bacteria (BDR) or in axenic media (ADR) (Klass, 1977; Hosono et al., 1989; Greer et al., 2007). Calorically restricting daf-2 or daf-16 mutants using BDR or ADR extends lifespan compared to daf-2 or daf-16 alone, suggesting that CR regulates aging independent of insulin signaling (Houthoofd et al., 2003; Crawford et al., 2007). Pharyngeal pumping mutants (e.g., eat-2) extend longevity due to defects in feeding (Raizen et al., 1995; Lakowski and Hekimi, 1998). Like direct CR, eat-2 regulates lifespan independent of insulin signaling, as eat-2; daf-2 double mutants live $20 \%$ longer than daf-2 alone (Crawford et al., 2007). The PHA4/FOXA1 transcription factor regulates CR-mediated longevity independently of its essential role in pharyngeal development (Panowski et al., 2007). Reducing pha-4 expression does not suppress the longevity of daf-2 or isp-1 mutants (Panowski et al., 2007), but PHA-4 activity is required for the lifespan extension of germline-less mutants (Hansen et al., 2008; Lapierre et al., 2011), suggesting that the germline and CR pathways may converge but that they are independent of IIS and mitochondrial longevity pathways. Adult-specific expression of pha-4 is required for the extended longevity of BDR-treated worms and of eat-2 mutants. The full complement of molecular mechanisms required for CRmediated longevity downstream of PHA-4/FOXA1 activity are not yet known.

\section{SENSORY SYSTEMS IN C. ELEGANS BEHAVIOR}

Despite the simplicity of this invertebrate system, the C. elegans model permits the analysis of both simple and complex behaviors at the individual gene level (reviewed in Hobert, 2003; de Bono and Maricq, 2005). C. elegans can sense and respond to temperature changes, gentle and harsh touch, $\mathrm{O}_{2}$ and $\mathrm{CO}_{2}$ concentration, and osmolarity, and can taste soluble chemicals and smell volatile odors (Ward, 1973; Dusenbery, 1974; Hedgecock and Russell, 1975; Culotti and Russell, 1978; Chalfie and Sulston, 1981; Bargmann et al., 1990; Bargmann and Horvitz, 1991; Gray et al., 2004; Bretscher et al., 2008; Hallem and Sternberg, 2008). Worms respond to these sensations by changing their normal locomotory behavior of smooth forward movement and turns (Croll, 1975; Niebur and Erdos, 1991) to instead chemotax using biased random walk and weathervane mechanisms (Pierce-Shimomura et al., 1999; Iino and Yoshida, 2009). C. elegans reverse in response to negative stimuli, suppress turns in response to attractive stimuli, adjust their speed and rate of body bends, and combine multiple behaviors to respond to more complex sensory environments (reviewed in Mori, 1999; Hobert, 2003; Bargmann, 2006; Goodman, 2006).

C. elegans integrate sensory stimuli and exhibit behavioral plasticity. Well-characterized forms of non-associative behavioral plasticity include adaptation to inherently attractive odors (Colbert and Bargmann, 1995) and habituation in response to multiple taps (Rankin et al., 1990). Associative behaviors include the ability to associate feeding state with temperature (thermotaxis) (Hedgecock and Russell, 1975; Mohri et al., 2005), salt concentration (salt learning) (Saeki et al., 2001), odor (olfactory learning) (Nuttley et al., 2002; Zhang et al., 2005; Torayama et al., 2007; Ha et al., 2010; Kauffman et al., 2010), and pathogenic state (Zhang et al., 2005). In addition to both associative and non-associative learning, C. elegans is able to form both short-term and long-term memories, lasting as long as $24 \mathrm{~h}$ (Rankin et al., 1990; Colbert and Bargmann, 1995; Gomez et al., 2001; Tomioka et al., 2006; 
Kano et al., 2008; Kauffman et al., 2010). While these behavioral phenotypes, as well as many of the genes regulating chemotaxis, thermotaxis, salt learning, adaptation, and habituation have been studied, very little is known about the specific molecular mechanisms involved in integrating multiple sensory signals (reviewed in de Bono and Maricq, 2005; Ardiel and Rankin, 2010).

\section{SENSORY NEURONS}

C. elegans has a simple nervous system that contains only 302 neurons. The positions of these neurons and their processes have been mapped and are highly stereotyped between individuals (White et al., 1986; Varshney et al., 2011). GFP fusions have been used to identify neuron-specific gene expression and protein localization in the transparent C. elegans (Chalfie et al., 1994; Nonet, 1999). Although electrophysiological techniques have been used to study the activity of specific neurons (Goodman et al., 1998; Lockery and Goodman, 1998; Richmond and Jorgensen, 1999), genetically encoded calcium indicators, such as Cameleon (Miyawaki et al., 1997; Kerr et al., 2000) and more recently, GCaMP (Nakai et al., 2001; Chronis et al., 2007; Tian et al., 2009), have allowed the measurement of neuronal activity in live, behaving worms, and the advent of microfluidic techniques has allowed the assessment of neuronal activity in response to stimuli (Suzuki et al., 2003; Chalasani et al., 2007; Chronis et al., 2007).

C. elegans has the ability to sense certain stimuli using only a single neuron or a subset of neurons. These sensory neurons communicate through interneurons and command interneurons to regulate motor neuron output and motor response to stimuli (reviewed in Hobert, 2003). Many neurons required to detect sensory stimuli have been identified, including those involved in odortaxis (AWA, AWB, AWC, ASH, and ADL), chemotaxis (ASE, ASK, ADF, ASG, and ASI), touch response (ALM, AVM, PVM, IL1, and OLQ) as well as many others involved in mechanosensory response to stimuli (reviewed in Bargmann and Kaplan, 1998) and thermotaxis (AFD, AWC, and ASI) (Mori and Ohshima, 1995; Biron et al., 2008; Kuhara et al., 2008; Beverly et al., 2011). The involvement of interneurons to mediate sensory output and integration is not as well understood, although circuits for thermotaxis, touch response, and chemotaxis that include interneurons such as AIA and AIY have been characterized using the original White et al. (1986) wiring diagram coupled with neuron ablation (Chalfie et al., 1985; Mori and Ohshima, 1995; Bargmann and Kaplan, 1998; Zheng et al., 1999; Tsalik and Hobert, 2003; Gray et al., 2005). Cell-specific genetic rescue (Mello et al., 1991), in vivo calcium imaging (Kerr et al., 2000; Suzuki et al., 2003; Chronis et al., 2007; Tian et al., 2009), electrophysiology (Goodman et al., 1998; Lockery and Goodman, 1998; Richmond and Jorgensen, 1999; Richmond et al., 1999), and genomic techniques (Wenick and Hobert, 2004) have been used to verify and refine these circuit models, which can then be used as a starting point when testing the neurons involved in specific behaviors.

\section{THE AGING NEURON}

Until recently, it was thought that $C$. elegans neurons did not show age-related morphological decline at either a cellular or subcellular level, because while other tissues, such as skin and muscle, deteriorate with age (Garigan et al., 2002), neurons remained surprisingly intact (Herndon et al., 2002). These data seem counterintuitive, considering multiple sensory behaviors as well as motility decline with age in C. elegans (Glenn et al., 2004; Murakami et al., 2005; Hsu et al., 2009; Kauffman et al., 2010; Guo et al., 2012) and changes in dendritic spines and synapse number with age have been observed in other organisms, including non-human primates and rats (reviewed in Burke and Barnes, 2006; Morrison and Baxter, 2012). Due to this incongruity, recent work has again tested the integrity of neurons and found that while neuronal cell bodies stay intact, neuronal processes, subcellular structures (Pan et al., 2011; Tank et al., 2011; Toth et al., 2012), and neuronal activity (Chokshi et al., 2010; Mulcahy et al., 2012) all show age-dependent changes.

Neuronal aging is associated with morphological changes that include ectopic neurite branching from the soma and processes, GFP beading within the process, and blebbing that results in a "wavy" process (Pan et al., 2011; Tank et al., 2011; Toth et al., 2012). Blebbing may be the precursor to neurite formation (Pan et al., 2011). The extent and type of abnormal cellular structures in aged animals is highly variable across neurons (Pan et al., 2011; Tank et al., 2011; Toth et al., 2012). Excess ectopic neurites are correlated with a decrease in gentle touch response and mobility (Tank et al., 2011), and neurite branching occurs as early as day 8 (Pan et al., 2011). While these experiments analyzed touch neurons and motor neurons that run along the C. elegans mid-section, Toth et al. (2012) found through analysis of EM images that synapses in the nerve ring and ventral ganglion are depleted of vesicles in day 15 animals. Older daf-2 worms have many fewer neuronal abnormalities with age than do similarly aged wild-type worms (Pan et al., 2011; Tank et al., 2011; Toth et al., 2012). The daf-2 slowed morphology change phenotype is dependent on daf-16 (Pan et al., 2011; Toth et al., 2012), and daf-16 mutants have increased neurite branching with age compared to wild-type (Pan et al., 2011; Tank et al., 2011). Tank et al. (2011) found that neuron-specific rescue of daf-16 in daf-16;daf-2 double mutants restored the daf-2 phenotype in mechanosensory neurons. Although Pan et al. (2011) found excessive neurite branching in $d a f-16$ mutants, they could not rescue this phenotype with neuron-specific daf-16 expression. Thus, it is unclear whether DAF-16 acts cell autonomously or non-autonomously to regulate neurite morphology with age.

The heat-shock transcription factor HSF-1 is required for daf2-mediated longevity, and functions with daf-16 to promote proteostasis and mediate longevity (Garigan et al., 2002; Hsu et al., 2003; Morley and Morimoto, 2004; Cohen et al., 2006). hsf-1 Mutants have significant increases in all age-related morphological changes in neurons (Pan et al., 2011; Toth et al., 2012). In addition to an excess of normal age-related changes, $h s f-1$ mutants also have breaks in their neuronal processes (Toth et al., 2012). hsf1;daf-16 Double mutants do not have more neuronal defects than single mutants and therefore, probably act in the same pathway to regulate neuronal aging (Pan et al., 2011).

Unlike insulin signaling mutants, eat-2 mutants have a long lifespan, but have normal rates of neurite branching with age (Tank et al., 2011). clk-1 Mutants have a phenotype that is similar to daf2 mutants, suppressing neurite outgrowth in older worms (Tank et al., 2011). Together, these data show that neuron morphology 
does change with age and is regulated by specific longevity pathways. Given that morphological defects such as abnormal branch formation are regulated during development and also arise with age, it would be interesting to test if pathways required for neuron development have an additional role in the regulation of neuron maintenance with age (Benard and Hobert, 2009).

Morphological changes in sensory neurons have not yet been reported. However, using microfluidics, Chokshi et al. (2010) found that the ASH sensory neuron's calcium response to glycerol changed with age. Specifically, day 1 adults had a lower peak response to glycerol than did days 3 or 4 adults, perhaps correlating with the peak reproductive period, but day 5 adults had a much smaller peak response than days 1-4. Chokshi et al. (2010) also identified oscillations in the calcium response to glycerol exposure of day 1 adult worms that were not present in days 3, 4, and 5 adult worms. The calcium responses of older C. elegans and/or other sensory neurons have not yet been investigated. Interestingly, mutants with defects in sensory cilia and worms with specific sensory neurons ablated are long-lived, suggesting that $C$. elegans lifespan is regulated by perception of its environment (Apfeld and Kenyon, 1999; Alcedo and Kenyon, 2004). Sensory mutant lifespan can be partially rescued in a daf-16 background, showing that extension is regulated in part by insulin signaling (Apfeld and Kenyon, 1999; Alcedo and Kenyon, 2004).

\section{LEARNING AND MEMORY PARADIGMS}

Associative learning and memory are acquired with training that pairs a conditioned stimulus with an unconditioned stimulus, known as "classical conditioning." First made famous by Pavlov's (1927) original experiment training dogs to associate food with a ringing bell, classical conditioning has been tested in organisms from Drosophila to mice, rats, and humans, and more recently, C. elegans. Many different classical conditioning paradigms have been used in human experiments, ranging from the original controversial Little Albert experiment in which a baby was trained to associate a white rat with a loud noise (Watson and Raynor, 1920), to more recent experiments associating neutral tones with harsh white noise (Hensman et al., 1991). Paradigms in model systems include training Drosophila, mice, or rats to associate neutral olfactory, auditory, or spatial cues with electric shock (Tully and Quinn, 1985).

Many forms of memory decline with age (reviewed in Morrison and Baxter, 2012), including associative memory decline in Drosophila (Tamura et al., 2003). C. elegans is able to perform a conditioned response after training in which food or starvation is associated with a conditioned stimulus (Hedgecock and Russell, 1975; Saeki et al., 2001; Nuttley et al., 2002; Torayama et al., 2007; Kauffman et al., 2010). Understanding the effects of aging and age-related genetic pathways on associative memory in C. elegans can lead to a greater understanding of mechanisms that may regulate associative memory in higher organisms. Agerelated experimental data using these paradigms are reviewed in detail below.

\section{THERMOTAXIS}

C. elegans can be conditioned to positively associate a training temperature with the presence of food (Hedgecock and Russell, 1975).
After training for four or more hours, worms move to their training temperature in search of food and navigate within this temperature for several hours, a behavior termed isothermal tracking (IT) (Mori and Ohshima, 1995; Mohri et al., 2005). Thermotactic ability is assessed using a single-worm assay in which worms are placed on a plate with a radial gradient of temperatures from 17 to $25^{\circ} \mathrm{C}$ for $90 \mathrm{~min}$, and worm tracks are analyzed to study IT (Mori and Ohshima, 1995; Gomez et al., 2001). Conversely, after starvation on a conditioning plate at a specific temperature, worms avoid that temperature (Mohri et al., 2005; Kodama et al., 2006) or no longer show a preference for that temperature (Chi et al., 2007). Chi et al. (2007) found that worms cultivated at $25^{\circ} \mathrm{C}$ did not migrate toward $25^{\circ} \mathrm{C}$, nor did worms starved at $25^{\circ} \mathrm{C}$ avoid warmer temperatures. The authors broadly interpreted their results to imply that thermotaxis is not a form of associative learning (Chi et al., 2007). However, Mohri et al. (2005) and Kodama et al. (2006) showed that worms are able to move toward $25^{\circ} \mathrm{C}$ when cultivated at that temperature, and avoid $25^{\circ} \mathrm{C}$ when starved at that temperature, suggesting that at least in some training paradigms, worms can form thermal food/starvations associations at $25^{\circ} \mathrm{C}$.

One mark of associative behavior is that it can be extinguished by reversing the association. Indeed, after conditioning worms overnight with food at $20^{\circ} \mathrm{C}$, Gomez et al. (2001) tested extinction of the temperature-food memory by holding the worms that had previously been cultivated at $20^{\circ} \mathrm{C}$ on plates without food at $20^{\circ} \mathrm{C}$. The number of worms showing IT decreased by $50 \%$ after about $7 \mathrm{~h}$ had elapsed since training, and returned to pre-conditioned levels by $18 \mathrm{~h}$ after training (Gomez et al., 2001). Long-lasting behavioral plasticity as a result of thermotaxis conditioning is modulated by diacylglycerol kinase at the sensory level in the neuron AFD (Biron et al., 2006). Diacylglycerol kinase is also known to regulate long-term reference memory in mice (Shirai et al., 2010). Whether or not thermotaxis meets other criteria of longterm memory, such as the requirements for protein translation, gene transcription, and CREB transcriptional activity, has not yet been tested.

Among worms showing locomotion, there is a moderate but significant decline in IT by day 6 of adulthood (Murakami and Murakami, 2005). By day 12 the fraction of worms with IT after training decreases by half, and is undetectable by day 15 (Murakami and Murakami, 2005). age-1 Mutants increase IT ability in young and old animals, and have a $210 \%$ extension in "high IT" ability (period where more than $75 \%$ of worms show IT), but only a $65 \%$ lifespan extension compared to wild-type worms (Murakami et al., 2005). Expression of age-1 in the AIY interneurons restored IT to wild-type levels, but did not affect lifespan, showing that AGE-1 functions directly in AIY neurons to mediate IT, rather than the phenotypic extension being a byproduct of organism-wide lifespan extension (Murakami et al., 2005; Kodama et al., 2006).

daf- 2 and age-1 mutants have increased IT as compared to wild-type worm when temperature is associated with either food or starvation in young adult worms and with age (Murakami et al., 2005). At both stages, the increase in IT is dependent on daf-16 (Murakami et al., 2005). The calcium-dependent gene ncs-1 is essential for IT (Gomez et al., 2001). ncs-1 Mutants have normal chemotaxis, motility, and thermal avoidance behaviors, but have 
reduced IT (Gomez et al., 2001). Murakami et al. (2005) tested ncs-1;daf-2 double mutants to determine whether or not ncs-1 genetically interacts with the insulin signaling pathway. ncs-1;daf2 Mutants have an IT defect compared to wild-type animals, but similar IT to both ncs-1 and daf-16 single mutants (Murakami et al., 2005). Though these data suggest that daf-2 is acting in an ncs-1-dependent manner in IT, Murakami et al. (2005) concede that $n c s-1$ may be essential for IT in any condition.

In a screen for mutants that do not integrate food conditions with temperature, Mohri et al. (2005) isolated an allele of ins-1. While wild-type animals avoid a temperature when it is paired with starvation, ins-1 mutants move toward their cultivation temperature regardless of the presence of food (Kodama et al., 2006). Kodama et al. (2006) showed that ins-1 mutants move and respond to feeding states normally, suggesting that they are specifically defective in forming the starvation-temperature association. daf2 and age- 1 mutants rescue the ins- 1 phenotype (Kodama et al., 2006). To analyze how ins-1 regulates IT, Kodama et al. (2006) analyzed calcium dynamics in the AIZ interneuron, which is essential for thermotaxis (Mori and Ohshima, 1995). In the presence of food, intracellular calcium is increased at higher temperatures and decreased at lower temperatures in wild-type animals (Kodama et al., 2006). The response of AIZ to temperature is dampened in starvation conditions in wild-type animals (Kodama et al., 2006). In ins-1 mutants, the response of AIZ to temperature is never dampened, suggesting that ins-1 regulates the integration of the starvation-temperature association (Kodama et al., 2006).

At both days 1 and 9 of adulthood, eat-2 mutants increase IT when associating food, but not starvation, with a specific temperature, indicating that CR affects food-temperature association (Murakami et al., 2005). The mitochondrial mutant $c l k-1$ also has increased IT at days 1 and 9 of adulthood (Murakami et al., 2005). Murakami and Murakami (2005) found that mutants with lower oxidative stress ( $c l k-1$ and isp-1), increased IT in young adults, while those with high levels of oxidative stress (gas-1 and mev1), decreased IT. Treating mev-1 mutants with the antioxidant lipoic acid partially rescued IT ability (Murakami and Murakami, 2005). C. elegans lifespan is shorter after long-term cultivation at higher temperatures (Klass, 1977). Thermotaxis associative learning assays show that C. elegans respond to even short-term changes in temperature and that these responses are temperature specific and also influenced by aging pathways.

\section{SALT CHEMOTAXIS LEARNING}

C. elegans can associate salt concentration with starvation conditions (Saeki et al., 2001). Untrained worms are attracted to $100 \mathrm{mM}$ salt, and this attraction is increased when worms are starved in buffer alone (Bargmann and Horvitz, 1991; Tomioka et al., 2006; Kano et al., 2008). Animals trained to associate salt with starvation remember this association for up to $60 \mathrm{~min}$, forming a stable short-term memory (Tomioka et al., 2006; Kano et al., 2008). Whether salt learning and memory change with age has not yet been tested.

After starvation in the presence of salt, the long-lived insulin signaling pathway mutants daf-2, age-1, pdk-1, and akt-1 are still attracted to salt (Tomioka et al., 2006), suggesting that they are defective in forming the starvation-salt association. Interestingly, loss of daf-16 does not rescue the daf- 2 or age- 1 mutant phenotypes, suggesting that the defect of daf-2 in salt learning is independent of daf-16 (Tomioka et al., 2006). Similar to thermotaxis, INS-1 was identified as the insulin-like peptide that may regulate this association, as ins-1 mutants show neither an avoidance of salt after starvation training nor an increased attraction to salt after starvation in the absence of salt (Tomioka et al., 2006). Salt learning is rescued by expression of age-1 or daf- 2 in the ASER neuron, and by ins-1 expression in AIA, suggesting that feedback between the AIA interneurons and the ASER sensory neuron results in associative learning that is mediated by INS-1 (Tomioka et al., 2006).

After conditioning without food in the presence of salt, the ASER neuron exhibits a sharp increase in calcium activity and a decrease in synaptic release following a down-step in salt concentration as compared to animals trained without salt (Oda et al., 2011). In the insulin signaling mutants daf-2, ins-1, and age-1, calcium signaling and synaptic release after salt conditioning are indistinguishable from mock-trained animals (Oda et al., 2011). Since insulin signaling in salt learning is active in ASER, this pathway may modulate activity and vesicle release specifically in ASER to reduce salt attraction. What salt response looks like with age and how insulin signaling regulates changes in calcium activity and synaptic function after salt learning remain to be tested.

\section{POSITIVE OLFACTORY ASSOCIATIVE LEARNING AND MEMORY}

Along with thermotaxis and salt learning, C. elegans can learn to associate an odor with food. Torayama et al. (2007) showed that after a single exposure to food and butanone, worms have a $20 \%$ increased chemotaxis index to butanone compared to naïve animals, termed "butanone enhancement" (Torayama et al., 2007). After conditioning worms for $90 \mathrm{~min}$, this enhancement lasted $4 \mathrm{~h}$ if they were starved after conditioning, but only $1 \mathrm{~h}$ if they were fed afterward (Torayama et al., 2007). The susceptibility of butanone enhancement to age-related decline and in longevity mutants has not been tested. ins-1 Mutants have normal butanone enhancement but cannot properly associate butanone with starvation (Lin et al., 2010).

In a different food/butanone training paradigm, Kauffman et al. (2010) found that worms that are briefly starved and then trained to associate butanone and food increase their chemotaxis toward butanone by $60 \%$. Using this paradigm, Kauffman et al. (2010) designed both massed- and spaced-training paradigms that result in short-term associative memory (STAM) and long-term associative memory (LTAM), respectively. Briefly, these assays involve a short starvation in buffer, followed by conditioning with food and butanone either once (massed training) or seven times (spacedtraining) (Kauffman et al., 2010). After training, worms are held on food without butanone (to allow them to forget the association) and are tested using a standard attraction chemotaxis assay (Troemel et al., 1997). STAM declines within $2 \mathrm{~h}$, but LTAM lasts between 16 and $24 \mathrm{~h}$ after training (Kauffman et al., 2010). LTAM is dependent on transcription, translation, and CREB activity (Kauffman et al., 2010), factors that have been shown in other organisms, such as flies, Aplysia, and mice, to be required for long-term memory (reviewed in Silva et al., 1998). 
To determine how aging affects associative memory in $C$. elegans, Kauffman et al. examined motility, chemotaxis, massed learning, spaced learning, and $16 \mathrm{~h}$ long-term memory for the first week of adulthood. While movement and chemotactic ability were maintained, $16 \mathrm{~h}$ LTAM decreased by day 2 of adulthood, and was undetectable by day 5 (Kauffman et al., 2010). Massed learning declined soon thereafter, while $7 \times$ spaced learning was undiminished at day 3, but declined by day 7 of adulthood (Kauffman et al., 2010). These cognitive declines precede age-related changes in chemotaxis, IT (Murakami and Murakami, 2005), habituation (Beck and Rankin, 1993), and motility, suggesting that $16 \mathrm{~h}$ LTAM and massed learning are most sensitive to age-related changes (Kauffman et al., 2010). Interestingly, this decline in cognitive function also occurs earlier than observable age-related morphological decline in neurons and muscles (Herndon et al., 2002; Pan et al., 2011; Tank et al., 2011; Toth et al., 2012).

Kauffman et al. (2010) next tested whether memory of positive olfactory conditioning in C. elegans is controlled by known longevity pathways, and found that (1) daf-2 mutants remember significantly longer than do wild-type animals on the first day of adulthood; (2) daf-2 mutant STAM lasts over three times as long as wild-type, and (3) daf-2 LTAM lasts longer than $40 \mathrm{~h}$ after training. The extension of learning and memory in daf2 mutants requires the DAF-16 transcription factor, as daf-16 mutants have defects in massed learning, STAM, and LTAM. daf-2 Mutants are also able to establish a 16-h long-term association after only five training sessions as compared to seven sessions for wild-type, although their massed learning rate is similar to wild-type's. To determine whether all longevity pathways have similar effects on learning and memory, Kauffman et al. (2010) also examined these behaviors in the CR model, eat-2. Unlike daf-2, eat-2 mutants have normal learning and shortterm memory, indicating that the feeding conditions used for training are not compromised in the eat-2 mutant, but that the STAM extension observed in daf-2 mutants is not generalizable to all longevity mutants. Additionally, eat-2's long-term memory is only $60 \%$ that of wild-type worms, suggesting that CR somehow impairs formation of the memory of the association between food and butanone, although LTAM can be restored by increasing training to 10 cycles (Kauffman et al., 2010). eat-2's Defective LTAM phenotypes are dependent on the pha-4 transcription factor (Kauffman et al., 2010), which is also required for eat-2's longevity effects (Panowski et al., 2007). Feeding eat-2 mutants a smaller, easier to digest bacteria, Comamonas sp., rescues their small body size (Avery and Shtonda, 2003) and reverses eat-2's lifespan extension (Kauffman et al., 2010), showing that Comamonas sp. feeding "undoes" CR. Kauffman et al. (2010) found that feeding eat-2 mutants Comamonas sp. also rescued eat-2's LTAM defect. Together, these results suggest that $C R$, rather than the acetylcholine receptor mutation that causes the defective pharyngeal pumping in eat-2 worms, is responsible for eat-2's memory defects (Kauffman et al., 2010). Therefore, different longevity pathways have different effects on learning and memory early in adulthood.

To determine the effects of the IIS and CR pathways on maintenance with age, Kauffman et al. tested the worms' performance on day 4 of adulthood. While eat- 2 animals have reduced $16 \mathrm{~h}$ memory on the first day of adulthood compared to wild-type worms, their memory ability is maintained at least until day 4 of adulthood and this maintenance also requires pha-4 (Kauffman et al., 2010). By contrast, daf-2 learning is maintained better than wild-type with age, but $16 \mathrm{~h}$ long-term memory at day 4 of adulthood is entirely abrogated, as it is in wild-type worms (Kauffman et al., 2010).

To resolve these seemingly disparate results, Kauffman et al. (2010) tested the cAMP response element binding protein (CREB) transcription factor, which is required for long-term memory in all organisms tested (reviewed in Silva et al., 1998) including C. elegans (Kauffman et al., 2010). Kauffman et al. examined whether CREB expression and activated protein levels correlated with LTAM retention in young, old, daf-2, and eat- 2 worms. Along with an increase in LTAM, daf-2 day 1 adults have higher levels of CREB protein than do day 1 wild-type worms (Kauffman et al., 2010). CREB levels and activity in both daf-2 and wild-type worms decrease with age, as does long-term memory (Kauffman et al., 2010). Conversely, eat-2 worms have lower levels of CREB and defective memory at day 1 of adulthood, but both CREB levels and day 1 adult long-term memory level are maintained with age (Kauffman et al., 2010). Therefore, the differential effects of the insulin and dietary restriction pathways with age could be attributable to their differences in CREB expression and activity levels, and CREB levels are predictive of memory performance.

These data agree with previous findings in mammals that show that along with decreased cognitive function, total CREB and CREB activity levels decline with age (Asanuma et al., 1996; Brightwell et al., 2004; Porte et al., 2008) and long-term memory can be rescued by over-expression of CREB in the hippocampus (Mouravlev et al., 2006). Therefore, the mechanisms required for CREB regulation of long-term memory in C. elegans may be conserved in higher organisms. Indeed, increased memory and neuronal plasticity in mice following CR requires CREB (Fusco et al., 2012); similar studies in IIS-reduced conditions in mice would be interesting to examine. Furthermore, the downstream targets of CREB that become activated upon memory training are presumably the cellular components that actually enable memory function, and therefore are important to identify. C. elegans presents a tractable system to identify genome-wide memoryspecific transcriptional targets of CREB, which can then be compared with CREB overexpression data (Barco et al., 2002) and Drosophila memory studies (Dubnau et al., 2003).

\section{OLFACTORY AVOIDANCE LEARNING}

After a single exposure to an aversive concentration of benzaldehyde and starvation, C. elegans avoids an attractive concentration of the same odor (Nuttley et al., 2002). Worms are starved in the presence of benzaldehyde and then tested for learning using an attraction chemotaxis assay (Troemel et al., 1997; Nuttley et al., 2002). This behavior is referred to as benzaldehyde-starvation associative plasticity. Whether this behavior is maintained or changes with age has not been reported. As in salt learning, ins-1, daf-2, and age-1 mutants lack the ability to fully associate benzaldehyde and starvation (Lin et al., 2010). Rescuing ins-1 only in adulthood or in AIA and ASI, two sets of interneurons, rescues the learning defect in these mutants (Lin et al., 2010). Rescuing age-1 
specifically in AWC, the neurons that sense benzaldehyde, rescues the learning defect.

Whether daf-2 primarily regulates memory recall or formation in massed benzaldehyde-starvation associative plasticity was addressed next (Lin et al., 2010). The daf-2(e1370) allele has temperature-sensitive learning phenotypes in both salt learning and olfactory avoidance learning (Tomioka et al., 2006; Lin et al., 2010). When conditioned and tested at $15^{\circ} \mathrm{C}$, daf-2's olfactory avoidance learning is normal, but when conditioned and tested at $23^{\circ} \mathrm{C}$, its learning is completely abrogated (Lin et al., 2010). Lin et al. (2010) found that training daf-2 mutants at the restrictive temperature $\left(23^{\circ} \mathrm{C}\right)$ resulted in memory formation if testing was done at the permissive temperature $\left(15^{\circ} \mathrm{C}\right)$. Conversely, training at $15^{\circ} \mathrm{C}$ then testing at the $23^{\circ} \mathrm{C}$ resulted in a lack of benzaldehydestarvation associative learning (Lin et al., 2010). Since testing daf-2 at the restrictive temperature after benzaldehyde-starvation training at either temperature shows a total loss of olfactory avoidance learning, but testing at the permissive temperature after training at the restrictive temperature shows only a small loss, daf-2 may function primarily in recall of olfactory avoidance learning. This agrees with the Kauffman et al. (2010) finding that daf-2 worms learn a butanone-food association at the same rate as wildtype, but retain a short-term memory of this association longer, and thus primarily affects recall, at least in a massed training paradigm.

\section{NON-ASSOCIATIVE LEARNING AND MEMORY}

Age-related decline and the effects of longevity pathways have been studied in some forms of associative learning and memory as reviewed above. However, less is known about the effect of aging on non-associative forms of memory. C. elegans can adapt to, be sensitized to, habituated to, or dishabituated to stimuli (Rankin et al., 1990; Colbert and Bargmann, 1995) as can higher organisms such as Drosophila, rats, and humans (Engen et al., 1963; Thompson and Spencer, 1966; Fox, 1979). Naïve response to tap and habituation change with age (Rankin et al., 1990; Beck and Rankin, 1993). Day 9 adult worms respond to tap with smaller reversals, and recover from habituation more slowly than do days 1 or 4 adult worms (Beck and Rankin, 1993). Like LTAM (Kauffman et al., 2010), early adulthood long-term memory of habituation requires CREB (Timbers and Rankin, 2011). It remains to be seen whether or not these age-related changes are regulated by longevity pathways.

C. elegans can also be trained to disregard an inherently attractive odor by long-term exposure to that odor, a form of olfactory adaptation (Colbert and Bargmann, 1995). Currently, age-related adaptation has not been tested. Murakami et al. (2005) found that daf- 2 mutants have increased adaptation to benzaldehyde. However, since worms are starved in the presence of benzaldehyde in this assay and learning is blocked by conditioning with food, they may in fact be forming a negative associative memory instead of adapting (Nuttley et al., 2002; Pereira and van der Kooy, 2012). Chalasani et al. (2010) found that ins-1(nr2091) mutants cannot adapt to isoamyl alcohol when starved. By contrast, Pereira and van der Kooy (2012) found that both daf-2 and ins-1(nj32) adapt normally after conditioning with isoamyl alcohol in the presence or absence of food.

\section{DISCUSSION}

\section{LEARNING AND MEMORY DECLINE WITH AGE}

Multiple forms of learning and memory decline with age in $C$. elegans as they do in Drosophila, mice, and humans (Bach et al., 1999; Tamura et al., 2003; Murakami and Murakami, 2005; Doty, 2009; Kauffman et al., 2010). In C. elegans cognitive decline occurs as early as day 2 of adulthood, when 16 h LTAM of an odor/food pairing is already significantly decreased (Kauffman et al., 2010). Figure 1 illustrates age-related declines in learning and memory (Figure 1A) as well as morphological changes in neurons with age (Figure 1B). The decline in IT could be explained by increased neuronal outgrowths and decreased synaptic vesicle density, but several types of learning and memory decline far before neurons exhibit these gross morphological changes. While changes in sensory neuron and interneuron subcellular structures may be responsible for early behavioral declines, there may be an earlier decline in neuronal signaling, due to changes in learning and memory gene expression levels. Indeed, Kauffman et al. (2010) found that reduction in CREB expression levels and activity with age correlate with reduced LTAM ability and occur far before structural and signaling changes are observed. Further analysis of neuronal activity using calcium indicators in multiple neurons could determine the full extent and timing of sensory decline with age.

\section{LONGEVITY PATHWAYS, LEARNING AND MEMORY}

Mutants in three longevity pathways have been tested in multiple learning paradigms. Phenotypes of different mutants are listed in Table 1. eat-2 CR mutants have enhanced associative thermotaxis (Murakami et al., 2005) and a defect in LTAM, but have stable long-term memory in the first 4 days of adulthood, unlike wildtype worms (Murakami et al., 2005; Kauffman et al., 2010). eat-2 Mutants have normal neuronal morphology with age (Tank et al., 2011). However, eat- 2 mutants have lower but stable CREB protein levels with age instead of decreasing levels as in wild-type worms, which may contribute to the stable LTAM phenotype (Kauffman et al., 2010). How CR enhances the thermotaxis/food association or affects CREB levels in this paradigm is unknown. Interestingly, short-term CR in older people was recently shown to improve verbal memory (recall of a word list after $30 \mathrm{~min}$ ) compared to controls (Witte et al., 2009). Increased insulin in humans through intranasal injection also improves verbal memory (Benedict et al., 2007).

The $c l k-1$ electron transport chain mutant has enhanced cellular integrity with age and enhanced positive thermotaxis (Murakami and Murakami, 2005; Tank et al., 2011). The increased thermotaxis is likely due to $c l k$-1's slower metabolism, as isp-1 also has increased thermotaxis, but mev-1 and gas-1, which have increased mitochondrial metabolic rates, display decreased thermotaxis (Murakami and Murakami, 2005; Murakami et al., 2005). While these data support the theory that ROS levels regulate age-related decline, whether or not mitochondrial metabolism or ROS is directly involved in learning and memory, or if the learning phenotype is instead a byproduct of the effects of slowed aging, is currently unknown.

The requirement of insulin signaling has been tested in multiple associative learning and memory paradigms. daf-2 Mutants 

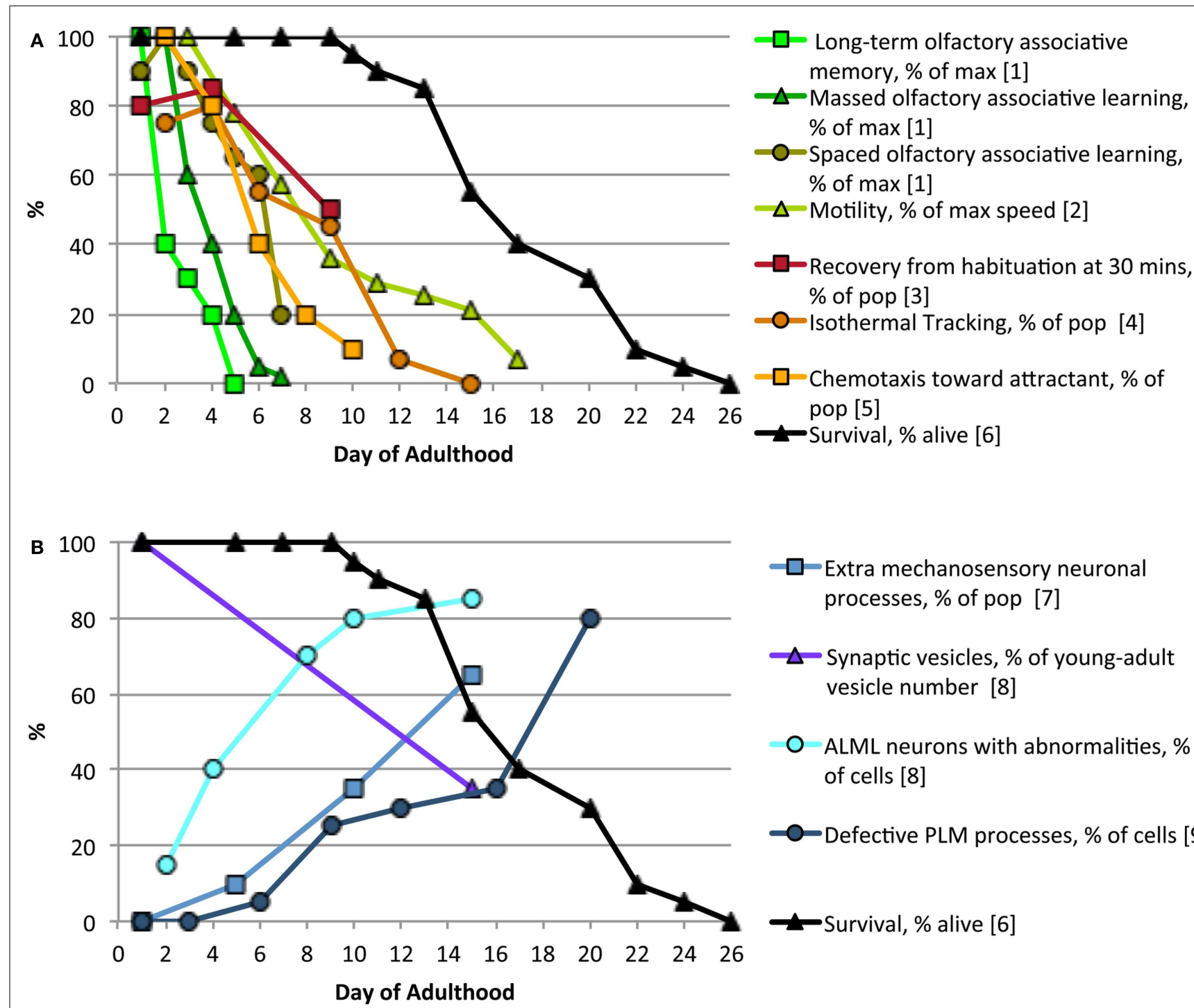
$\square$-Extra mechanosensory neuronal processes, \% of pop [7]

$\triangle$ Synaptic vesicles, $\%$ of young-adult vesicle number [8]

O-ALML neurons with abnormalities, $\%$ of cells [8]

-Defective PLM processes, \% of cells [9]

FIGURE 1 | Age-related changes in neuron morphology and behavior. Behaviors based on sensory perception (A) decline rapidly with age, preceding accumulation of most identified neuronal defects (B), long before worms start to die [solid black line in $(\mathbf{A}, \mathbf{B})$ ]. Complex sensory behaviors, such as long-term associative memory, decline prior to mechanosensory behaviors, such as locomotion. References: (1) Kauffman et al., 2010, (2) Hsu et al., 2009, (3) Beck and Rankin, 1993, (4) Murakami and Murakami, 2005, (5) Glenn et al., 2004, (6) Luo et al., 2009, (7) Tank et al., 2011, (8) Toth et al., 2012, (9) Pan et al., 2011. appear to differentially regulate different learning paradigms, as they have enhanced thermotaxis (Murakami et al., 2005), longterm and short-term positive associative learning and memory (Kauffman et al., 2010), and improved neuron integrity (Pan et al., 2011; Tank et al., 2011; Toth et al., 2012), but are deficient in salt learning (Tomioka et al., 2006) and olfactory avoidance learning (Lin et al., 2010). The inability of daf-2 mutants to perform the two latter forms of learning, which rely on negative associations, perhaps indicates that daf2 mutants are unable to form negative associations as readily as wild-type. Since daf-2 mutants are more resistant to stresses such as heat, paraquat, and starvation in low bacteria concentrations (Houthoofd et al., 2003), they may need increased conditioning time or more extreme stress conditions to form negative associations.

Unlike mitochondrial metabolism, it is clear that insulin signaling regulates learning separately from longevity, since neuronspecific rescue of daf-2, age-1, or daf-16 can rescue learning phenotypes without restoring normal lifespan (Murakami et al., 2005; Kodama et al., 2006; Tomioka et al., 2006; Lin et al., 2010). This may simply be a result of the cell autonomous nature of neuronal phenotypes, as opposed to the system-wide nature of longevity and dauer regulation (Apfeld and Kenyon, 1998). daf-2 Mutants have higher CREB levels and increased long-term associative 
Table 1 | Longevity pathway mutant phenotypes compared to wild-type worms.

\begin{tabular}{|c|c|c|c|c|c|c|}
\hline Phenotype with respect to wild-type & ins-1 & daf-2 & age-1 & daf-16 & eat-2 & $c / k-1$ \\
\hline Neuron integrity (Pan et al., 2011; Tank et al., 2011) & $n / d$ & + & $n / d$ & - & No change & + \\
\hline $\begin{array}{l}\text { Positive associative thermotaxis (Murakami and Murakami, 2005; } \\
\text { Murakami et al., 2005) }\end{array}$ & No change & + & + & - & + & + \\
\hline $\begin{array}{l}\text { Negative associative thermotaxis (Murakami and Murakami, 2005; } \\
\text { Murakami et al., 2005) }\end{array}$ & - & + & + & - & No change & No change \\
\hline Salt learning (Tomioka et al., 2006) & - & - & - & - & Naïve defect & $\mathrm{n} / \mathrm{d}$ \\
\hline Olfactory adaptation (Chalasani et al., 2010, Pereira and van der Kooy, 2012) & - & + & $n / d$ & $\mathrm{n} / \mathrm{d}$ & $\mathrm{n} / \mathrm{d}$ & $\mathrm{n} / \mathrm{d}$ \\
\hline Massed positive olfactory learning (Kauffman et al., 2010; Lin et al., 2010) & No change & No change & $\mathrm{n} / \mathrm{d}$ & - & No change & $\mathrm{n} / \mathrm{d}$ \\
\hline Short-term associative memory (Kauffman et al., 2010) & $\mathrm{n} / \mathrm{d}$ & + & $\mathrm{n} / \mathrm{d}$ & - & No change & $\mathrm{n} / \mathrm{d}$ \\
\hline Spaced olfactory learning (Kauffman et al., 2010) & $n / d$ & No change & $\mathrm{n} / \mathrm{d}$ & - & No change & $\mathrm{n} / \mathrm{d}$ \\
\hline Long-term associative memory (Kauffman et al., 2010) & $\mathrm{n} / \mathrm{d}$ & + & $n / d$ & - & - & $\mathrm{n} / \mathrm{d}$ \\
\hline Olfactory avoidance learning (Lin et al., 2010) & - & - & - & $n / d$ & $\mathrm{n} / \mathrm{d}$ & $n / d$ \\
\hline
\end{tabular}

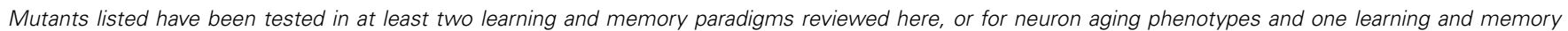
paradigm reviewed here.

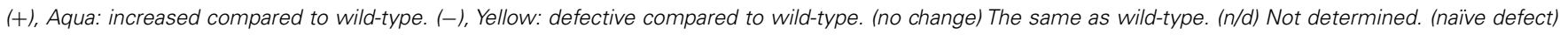
Chemotaxis defect before training.

olfactory memory as well as extended learning and STAM with age (Kauffman et al., 2010). For thermotaxis and positive associative olfactory learning and memory, it may be interesting to test downstream targets of daf-16 for learning and memory effects. However, daf-2 mutant response to salt learning is independent of daf-16 and may rely on different daf-2 signaling output. daf-2 Mutants (as compared to daf-16;daf-2 mutants) expressed lower levels of the guanylyl cyclases $g c y-18$ and $g c y-6$ (Murphy et al., 2003). As these genes are normally expressed in neurons required for thermotaxis (AFD) and salt learning (ASE), respectively, some of daf-2's defects may be due to altered signaling within those neurons.

ins-1 May be the cue for integration of a starvation-stimulus association, but not a food-stimulus association. ins-1 Mutants are still attracted to odors, salt, and temperature even after starvation (Mohri et al., 2005; Tomioka et al., 2006; Lin et al., 2010). Rescuing ins-1 expression in the AIA interneuron restores both salt and olfactory avoidance learning (Tomioka et al., 2006; Lin et al., 2010). This is especially intriguing since rescue of daf-2 or age-1 in the sensory neurons ASER or AWC restores normal behavior in olfactory avoidance learning and salt learning, respectively (Tomioka et al., 2006; Lin et al., 2010). These data inform a model in which INS-1 is secreted by AIA after association of starvation with a stimulus, and acts in a feedback loop to regulate insulin signaling in the sensory cells (Chalasani et al., 2010). The

\section{REFERENCES}

Adachi, H., Fujiwara, Y., and Ishii, N. (1998). Effects of oxygen on protein carbonyl and aging in Caenorhabditis elegans mutants with long (age$1)$ and short (mev-1) life spans. J. Gerontol. A Biol. Sci. Med. Sci. 53, B240-B244.

Alcedo, J., and Kenyon, C. (2004). Regulation of C. elegans longevity by

mechanism of INS-1 secretion in AIA and the downstream effects on insulin signaling in the sensory neurons are unknown, though Chalasani et al. (2010) found that ins-1 does not require daf-2 for regulation of turning behavior, suggesting that INS-1 can act through a different and as yet unidentified receptor. This would be an interesting alternative to the " 40 insulins/one insulin receptor" model of insulin signaling in C. elegans. Because daf-2, age-1, and ins-1 mutants have defective AIZ interneuron responses to starvation and thermotaxis, ins-1 may also regulate insulin signaling in downstream interneurons (Kodama et al., 2006).

\section{CONCLUSION}

C. elegans is an established organism in the field of aging and longevity, as well as a model for complex behaviors, such as learning and memory. While many organisms show age-related declines in learning and memory, few molecular mechanisms that regulate these processes have been identified. Since longevity pathways actively regulate learning and memory declines and morphological changes in neurons, $C$. elegans will be an ideal system to identify molecular mechanisms that regulate such declines. Our understanding of both normal aging and neurodegenerative disease-related decreases in learning and memory at a cellular, synaptic, and molecular level will be aided by further $C$. elegans investigations at the intersection of aging, longevity, and neurobiology.

diapause and life span. Cell 95, 199-210.

Apfeld, J., and Kenyon, C. (1999). Regulation of lifespan by sensory perception in Caenorhabditis elegans. Nature 402, 804-809.

Ardiel, E. L., and Rankin, C. H. (2010). An elegant mind: learning and memory in Caenorhabditis elegans. Learn. Mem. 17, 191-201.
Asanuma, M., Nishibayashi, S., Iwata, E., Kondo, Y., Nakanishi, T., Vargas, M. G., et al. (1996). Alterations of cAMP response elementbinding activity in the aged rat brain in response to administration of rolipram, a cAMPspecific phosphodiesterase inhibitor. Brain Res. Mol. Brain Res. 41, 210-215. 
Avery, L., and Horvitz, H. R. (1989). Pharyngeal pumping continues after laser killing of the pharyngeal nervous system of C. elegans. Neuron 3 , 473-485.

Avery, L., and Shtonda, B. B. (2003). Food transport in the C-elegans pharynx. J. Exp. Biol. 206, 2441-2457.

Bach, M. E., Barad, M., Son, H., Zhuo, M., Lu, Y. F., Shih, R., et al. (1999). Age-related defects in spatial memory are correlated with defects in the late phase of hippocampal longterm potentiation in vitro and are attenuated by drugs that enhance the cAMP signaling pathway. Proc. Natl. Acad. Sci. U.S.A. 96, 5280-5285.

Barco, A., Alarcon, J. M., and Kandel, E. R. (2002). Expression of constitutively active CREB protein facilitates the late phase of long-term potentiation by enhancing synaptic capture. Cell 108, 689-703.

Bargmann, C. I. (2006). "Chemosensation in C. elegans," in WormBook, ed. The C. elegans Research Community (WormBook), doi/10.1895/ wormbook.1.123.1. Available at: http://www.wormbook.org

Bargmann, C. I., and Horvitz, H. R. (1991). Chemosensory neurons with overlapping functions direct chemotaxis to multiple chemicals in C. elegans. Neuron 7, 729-742.

Bargmann, C. I., and Kaplan, J. M. (1998). Signal transduction in the Caenorhabditis elegans nervous system. Annu. Rev. Neurosci. 21, 279-308.

Bargmann, C. I., Thomas, J. H., and Horvitz, H. R. (1990). Chemosensory cell function in the behavior and development of Caenorhabditis elegans. Cold Spring Harb. Symp. Quant. Biol. 55, 529-538.

Beck, C. D. O., and Rankin, C. H. (1993). Effects of aging on habituation in the nematode Caenorhabditis elegans. Behav. Processes 28, 145-163.

Benard, C., and Hobert, O. (2009). Looking beyond development: maintaining nervous system architecture. Curr. Top. Dev. Biol. 87, 175-194.

Benedict, C., Hallschmid, M., Schultes, B., Born, J., and Kern, W. (2007). Intranasal insulin to improve memory function in humans. Neuroendocrinology 86, 136-142.

Beverly, M., Anbil, S., and Sengupta, P. (2011). Degeneracy and neuromodulation among thermosensory neurons contribute to robust thermosensory behaviors in Caenorhabditis elegans. J. Neurosci. 31, 11718-11727.
Biron, D., Shibuya, M., Gabel, C., Wasserman, S. M., Clark, D. A., Brown, A., et al. (2006). A diacylglycerol kinase modulates long-term thermotactic behavioral plasticity in C. elegans. Nat. Neurosci. 9, 1499-1505.

Biron, D., Wasserman, S., Thomas, J. H., Samuel, A. D., and Sengupta, P. (2008). An olfactory neuron responds stochastically to temperature and modulates Caenorhabditis elegans thermotactic behavior. Proc. Natl. Acad. Sci. U.S.A. 105, 11002-11007.

Bluher, M., Kahn, B. B., and Kahn, C. R. (2003). Extended longevity in mice lacking the insulin receptor in adipose tissue. Science 299, 572-574.

Brenner, S. (1974). The genetics of Caenorhabditis elegans. Genetics 77, 71-94.

Bretscher, A. J., Busch, K. E., and De Bono, M. (2008). A carbon dioxide avoidance behavior is integrated with responses to ambient oxygen and food in Caenorhabditis elegans. Proc. Natl. Acad. Sci. U.S.A. 105, 8044-8049.

Brightwell, J. J., Gallagher, M., and Colombo, P. J. (2004). Hippocampal CREB1 but not CREB2 is decreased in aged rats with spatial memory impairments. Neurobiol. Learn. Mem. 81, 19-26.

Burke, S. N., and Barnes, C. A. (2006). Neural plasticity in the ageing brain. Nat. Rev. Neurosci. 7, 30-40.

Chalasani, S. H., Chronis, N., Tsunozaki, M., Gray, J. M., Ramot, D., Goodman, M. B., et al. (2007). Dissecting a circuit for olfactory behaviour in Caenorhabditis elegans. Nature 450, 63-70.

Chalasani, S. H., Kato, S., Albrecht, D. R., Nakagawa, T., Abbott, L. F., and Bargmann, C. I. (2010). Neuropeptide feedback modifies odor-evoked dynamics in Caenorhabditis elegans olfactory neurons. Nat. Neurosci. 13, 615-621.

Chalfie, M., and Sulston, J. (1981). Developmental genetics of the mechanosensory neurons of Caenorhabditis elegans. Dev. Biol. 82, 358-370.

Chalfie, M., Sulston, J. E., White, J. G., Southgate, E., Thomson, J. N., and Brenner,S. (1985). The neural circuit for touch sensitivity in Caenorhabditis elegans. J. Neurosci. 5, 956-964.

Chalfie, M., Tu, Y., Euskirchen, G., Ward, W. W., and Prasher, D. C. (1994). Green fluorescent protein as a marker for gene expression. Science 263, 802-805.

Chi, C. A., Clark, D. A., Lee, S., Biron, D., Luo, L., Gabel, C. V., et al. (2007).
Temperature and food mediate longterm thermotactic behavioral plasticity by association-independent mechanisms in C. elegans. J. Exp. Biol. 210, 4043-4052.

Chokshi, T. V., Bazopoulou, D., and Chronis, N. (2010). An automated microfluidic platform for calcium imaging of chemosensory neurons in Caenorhabditis elegans. Lab. Chip 10, 2758-2763.

Chronis, N., Zimmer, M., and Bargmann, C. I. (2007). Microfluidics for in vivo imaging of neuronal and behavioral activity in Caenorhabditis elegans. Nat. Methods 4, 727-731.

Clancy, D. J., Gems, D., Harshman, L. G., Oldham, S., Stocker, H., Hafen, E., et al. (2001). Extension of life-span by loss of CHICO, a Drosophila insulin receptor substrate protein. Science 292, 104-106.

Cohen, E., Bieschke, J., Perciavalle, R. M., Kelly, J. W., and Dillin, A. (2006). Opposing activities protect against age-onset proteotoxicity. $\mathrm{Sci}$ ence 313, 1604-1610.

Colbert, H. A., and Bargmann, C. I. (1995). Odorant-specific adaptation pathways generate olfactory plasticity in C. elegans. Neuron 14, 803-812.

Crawford, D., Libina, N., and Kenyon, C. (2007). Caenorhabditis elegans integrates food and reproductive signals in lifespan determination. Aging Cell 6, 715-721.

Crawford, D. R., Abramova, N. E., and Davies, K. J. A. (1998). Oxidative stress causes a general, calcium-dependent degradation of mitochondrial polynucleotides. Free Radic. Biol. Med. 25, 1106-1111.

Croll, N. A. (1975). Behavioural analysis of nematode movement. Adv. Parasitol. 13, 71-122.

Culotti, J. G., and Russell, R. L. (1978). Osmotic avoidance defective mutants of the nematode Caenorhabditis elegans. Genetics 90 243-256.

de Bono, M., and Marica, A. V. (2005). Neuronal substrates of complex behaviors in C. elegans. Annu. Rev. Neurosci. 28, 451-501.

Dillin, A., Hsu, A. L., ArantesOliveira, N., Lehrer-Graiwer, J., Hsin, H., Fraser, A. G., et al. (2002). Rates of behavior and aging specified by mitochondrial function during development. Science 298, 2398-2401.

Dorman, J. B., Albinder, B., Shroyer, T., and Kenyon, C. (1995). The age-1 and daf- 2 genes function in a common pathway to control the lifespan of Caenorhabditis elegans. Genetics 141, 1399-1406.

Doty, R. L. (2009). The olfactory system and its disorders. Semin. Neurol. 29, 74-81.

Dubnau, J., Chiang, A. S., Grady, L., Barditch, J., Gossweiler, S., McNeil, J., et al. (2003). The staufen/pumilio pathway is involved in Drosophila long-term memory. Curr. Biol. 13, 286-296.

Dusenbery, D. B. (1974). Analysis of chemotaxis in the nematode Caenorhabditis elegans by countercurrent separation. J. Exp. Zool. 188 41-47.

Engen, T., Lipsitt, L. P., and Kaye, H. (1963). Olfactory responses and adaptation in the human neonate. $J$. Comp. Physiol. Psychol. 56, 73-77.

Felix, M. A., and Braendle, C. (2010). The natural history of Caenorhabditis elegans. Curr. Biol. 20, R965R969.

Feng, J., Bussiere, F., and Hekimi, S. (2001). Mitochondrial electron transport is a key determinant of life span in Caenorhabditis elegans. Dev. Cell 1, 633-644.

Fox, J. E. (1979). Habituation and prestimulus inhibition of the auditory startle reflex in decerebrate rats. Physiol. Behav. 23, 291-297.

Friedman, D. B., and Johnson, T. E. (1988). A mutation in the age-1 gene in Caenorhabditis elegans lengthens life and reduces hermaphrodite fertility. Genetics 118, 75-86.

Fusco, S., Ripoli, C., Podda, M. V., Ranieri, S. C., Leone, L., Toietta, G. et al. (2012). A role for neuronal cAMP responsive-element binding (CREB)- 1 in brain responses to calorie restriction. Proc. Natl. Acad. Sci. U.S.A. 109, 621-626.

Garigan, D., Hsu, A. L., Fraser, A. G., Kamath, R. S., Ahringer, J., and Kenyon, C. (2002). Genetic analysis of tissue aging in Caenorhabditis elegans: a role for heat-shock factor and bacterial proliferation. Genetics 161, 1101-1112.

Glenn, C. F., Chow, D. K., David, L., Cooke, C. A., Gami, M. S., Iser, W. B., et al. (2004). Behavioral deficits during early stages of aging in Caenorhabditis elegans result from locomotory deficits possibly linked to muscle frailty. J. Gerontol. A Biol. Sci. Med. Sci. 59, 1251-1260.

Gomez, M., De Castro, E., Guarin, E., Sasakura, H., Kuhara, A., Mori, I., et al. (2001). Ca2+ signaling via the neuronal calcium sensor-1 regulates associative learning and memory in C. elegans. Neuron 30, 241-248.

Goodman, M. B. (2006). "Mechanosensation," in WormBook, ed. The 
C. elegans Research Community (WormBook), doi/10.1895/ wormbook.1.62.1. Available at: http://www.wormbook.org

Goodman, M. B., Hall, D. H., Avery, L., and Lockery, S. R. (1998). Active currents regulate sensitivity and dynamic range in C. elegans neurons. Neuron 20, 763-772.

Gray, J. M., Hill, J. J., and Bargmann, C. I. (2005). A circuit for navigation in Caenorhabditis elegans. Proc. Natl. Acad. Sci. U.S.A. 102, 3184-3191.

Gray, J. M., Karow, D. S., Lu, H., Chang, A. J., Chang, J. S., Ellis, R. E., et al. (2004). Oxygen sensation and social feeding mediated by a C. elegans guanylate cyclase homologue. Nature 430, 317-322.

Greer, E. L., Dowlatshahi, D., Banko, M. R., Villen, J., Hoang, K., Blanchard, D., et al. (2007). An AMPK-FOXO pathway mediates longevity induced by a novel method of dietary restriction in C-elegans. Curr. Biol. 17, 1646-1656.

Grune, T., Reinheckel, T., and Davies, K. J. A. (1997). Degradation of oxidized proteins in mammalian cells. FASEB J. 11, 526-534.

Guo, X., Navetta, A., Gualberto, D. G., and Garcia, L. R. (2012). Behavioral decay in aging male C. elegans correlates with increased cell excitability. Neurobiol. Aging 33, 1483 e14851483 e1423.

Ha, H. I., Hendricks, M., Shen, Y., Gabel, C. V., Fang-Yen, C., Qin, Y., et al. (2010). Functional organization of a neural network for aversive olfactory learning in Caenorhabditis elegans. Neuron 68, 1173-1186.

Hallem, E. A., and Sternberg, P. W. (2008). Acute carbon dioxide avoidance in Caenorhabditis elegans. Proc. Natl. Acad. Sci. U.S.A. 105, 8038-8043.

Hansen, M., Chandra, A., Mitic, L. L., Onken, B., Driscoll, M., and Kenyon, C. (2008). A role for autophagy in the extension of lifespan by dietary restriction in C. elegans. PLoS Genet. 4, e24. doi:10.1371/journal.pgen.0040024

Harris, G., Korchnak, A., Summers, P., Hapiak, V., Law, W. J., Stein, A. M., et al. (2011). Dissecting the serotonergic food signal stimulating sensory-mediated aversive behavior in C. elegans. PLoS ONE 6, e21897. doi:10.1371/journal.pone.0021897

Hedgecock, E. M., and Russell, R. L. (1975). Normal and mutant thermotaxis in the nematode Caenorhabditis elegans. Proc. Natl. Acad. Sci. U.S.A. 72, 4061-4065.
Hensman, R., Guimaraes, F. S., Wang, M., and Deakin, J. F. (1991). Effects of ritanserin on aversive classical conditioning in humans. Psychopharmacology (Berl.) 104, 220-224.

Herndon, L. A., Schmeissner, P. J., Dudaronek, J. M., Brown, P. A., Listner, K. M., Sakano, Y., et al. (2002). Stochastic and genetic factors influence tissue-specific decline in ageing C. elegans. Nature 419, 808-814.

Hobert, O. (2003). Behavioral plasticity in C. elegans: paradigms, circuits, genes. J. Neurobiol. 54, 203-223.

Hosono, R., Nishimoto, S., and Kuno, S. (1989). Alterations of life span in the nematode Caenorhabditis elegans under monoxenic culture conditions. Exp. Gerontol. 24, 251-264.

Houthoofd, K., Braeckman, B. P., Johnson, T. E., and Vanfleteren, J. R. (2003). Life extension via dietary restriction is independent of the Ins/IGF-1 signalling pathway in Caenorhabditis elegans. Exp. Gerontol. 38, 947-954.

Hsu, A. L., Feng, Z., Hsieh, M. Y., and Xu, X. Z. (2009). Identification by machine vision of the rate of motor activity decline as a lifespan predictor in C. elegans. Neurobiol. Aging 30, 1498-1503.

Hsu, A. L., Murphy, C. T., and Kenyon, C. (2003). Regulation of aging and age-related disease by DAF-16 and heat-shock factor. Science 300, 1142-1145.

Iino, Y., and Yoshida, K. (2009). Parallel use of two behavioral mechanisms for chemotaxis in Caenorhabditis elegans. J. Neurosci. 29, 5370-5380.

Ishii, N., Fujii, M., Hartman, P. S., Tsuda, M., Yasuda, K., Senoo-Matsuda, N., et al. (1998). A mutation in succinate dehydrogenase cytochrome b causes oxidative stress and ageing in nematodes. Nature 394, 694-697.

Kano, T., Brockie, P. J., Sassa, T., Fujimoto, H., Kawahara, Y., Iino, Y., et al. (2008). Memory in Caenorhabditis elegans is mediated by NMDAtype ionotropic glutamate receptors. Curr. Biol. 18, 1010-1015.

Kauffman, A. L., Ashraf, J. M., CorcesZimmerman, M. R., Landis, J. N., and Murphy, C. T. (2010). Insulin signaling and dietary restriction differentially influence the decline of learning and memory with age. PLoS Biol. 8, e1000372. doi:10.1371/journal.pbio.1000372

Kayser, E. B., Morgan, P. G., Hoppel, C. L., and Sedensky, M. M. (2001). Mitochondrial expression and function of GAS-1 in
Caenorhabditis elegans. J. Biol. Chem. 276, 20551-20558.

Kayser, E. B., Sedensky, M. M., and Morgan, P. G. (2004). The effects of complex I function and oxidative damage on lifespan and anesthetic sensitivity in Caenorhabditis elegans. Mech. Ageing Dev. 125, 455-464.

Kenyon, C., Chang, J., Gensch, E., Rudner, A., and Tabtiang, R. (1993). A C. elegans mutant that lives twice as long as wild type. Nature 366, 461-464.

Kerr, R., Lev-Ram, V., Baird, G., Vincent, P., Tsien, R. Y., and Schafer, W. R. (2000). Optical imaging of calcium transients in neurons and pharyngeal muscle of C. elegans. Neuron 26, 583-594.

Kimble, J., and Hirsh, D. (1979). The postembryonic cell lineages of the hermaphrodite and male gonads in Caenorhabditis elegans. Dev. Biol. 70, 396-417.

Kimura, K. D., Tissenbaum, H. A., Liu, Y., and Ruvkun, G. (1997). daf-2, an insulin receptor-like gene that regulates longevity and diapause in Caenorhabditis elegans. Science 277, 942-946.

Klass, M. R. (1977). Aging in the nematode Caenorhabditis elegans: major biological and environmental factors influencing life span. Mech. Ageing Dev. 6, 413-429.

Kodama, E., Kuhara, A., Mohri-Shiomi, A., Kimura, K. D., Okumura, M., Tomioka, M., et al. (2006). Insulinlike signaling and the neural circuit for integrative behavior in C. elegans. Genes Dev. 20, 2955-2960.

Kowaltowski, A. J., De Souza-Pinto, N. C., Castilho, R. F., and Vercesi, A. E. (2009). Mitochondria and reactive oxygen species. Free Radic. Biol. Med. 47, 333-343.

Kuhara, A., Okumura, M., Kimata, T. Tanizawa, Y., Takano, R., Kimura, K. D., et al. (2008). Temperature sensing by an olfactory neuron in a circuit controlling behavior of $\mathrm{C}$. elegans. Science 320, 803-807.

Lai, C. H., Chou, C. Y., Ch'Ang, L. Y. Liu, C. S., and Lin, W. (2000). Identification of novel human genes evolutionarily conserved in Caenorhabditis elegans by comparative proteomics. Genome Res. 10, 703-713.

Lakowski, B., and Hekimi, S. (1998). The genetics of caloric restriction in Caenorhabditis elegans. Proc. Natl. Acad. Sci. U.S.A. 95, 13091-13096.

Lapierre, L. R., Gelino, S., Melendez, A., and Hansen, M. (2011). Autophagy and lipid metabolism coordinately modulate life span in germline-less C. elegans. Curr. Biol. 21, 1507-1514.
Lee, S. S., Lee, R. Y., Fraser, A. G., Kamath, R. S., Ahringer, J., and Ruvkun, G. (2003). A systematic RNAi screen identifies a critical role for mitochondria in C. elegans longevity. Nat. Genet. 33, 40-48.

Lewis, J. A., Wu, C. H., Levine, J. H., and Berg, H. (1980). Levamisoleresistant mutants of the nematode Caenorhabditis elegans appear to lack pharmacological acetylcholine receptors. Neuroscience 5, 967-989.

Li, W., Kennedy, S. G., and Ruvkun, G. (2003). daf-28 encodes a C. elegans insulin superfamily member that is regulated by environmental cues and acts in the DAF-2 signaling pathway. Genes Dev. 17, 844-858.

Lin, C. H., Tomioka, M., Pereira, S., Sellings, L., Iino, Y., and Van Der Kooy, D. (2010). Insulin signaling plays a dual role in Caenorhabditis elegans memory acquisition and memory retrieval. J. Neurosci. 30, 8001-8011.

Lin, K., Hsin, H., Libina, N., and Kenyon, C. (2001). Regulation of the Caenorhabditis elegans longevity protein DAF-16 by insulin/IGF-1 and germline signaling. Nat. Genet. 28, 139-145.

Lin, S. J., Defossez, P. A., and Guarente, L. (2000). Requirement of NAD and SIR2 for life-span extension by calorie restriction in Saccharomyces cerevisiae. Science 289, 2126-2128.

Lockery, S. R., and Goodman, M. B. (1998). Tight-seal whole-cell patch clamping of Caenorhabditis elegans neurons. Meth. Enzymol. 293, 201-217.

Luo, S., Shaw, W. M., Ashraf, J., and Murphy, C. T. (2009). TGF-beta Sma/Mab signaling mutations uncouple reproductive aging from somatic aging. PLoS Genet. 5, e1000789. doi:10.1371/journal.pgen.1000789

McCay, C. M., and Crowell, M. F. (1934). Prolonging the Life Span. Sci. Mon. 39, 405-414.

McCay, C. M., Crowell, M. F., and Maynard, L. M. (1935). The effect of retarded growth upon the life span and upon the ultimate body size. $J$. Nutr. 10, 63-79.

Mello, C. C., Kramer, J. M., Stinchcomb, D., and Ambros, V. (1991) Efficient gene transfer in C. elegans: extrachromosomal maintenance and integration of transforming sequences. $E M B O ~ J . ~ 10$, 3959-3970.

Miyadera, H., Amino, H., Hiraishi, A., Taka, H., Murayama, K., Miyoshi, H., et al. (2001). Altered quinone biosynthesis in the long-lived clk-1 
mutants of Caenorhabditis elegans. J. Biol. Chem. 276, 7713-7716.

Miyawaki, A., Llopis, J., Heim, R., McCaffery, J. M., Adams, J. A., Ikura, M., et al. (1997). Fluorescent indicators for $\mathrm{Ca} 2+$ based on green fluorescent proteins and calmodulin. Nature 388, 882-887.

Mohri, A., Kodama, E., Kimura, K. D., Koike, M., Mizuno, T., and Mori, I. (2005). Genetic control of temperature preference in the nematode Caenorhabditis elegans. Genetics 169, 1437-1450.

Mori, I. (1999). Genetics of chemotaxis and thermotaxis in the nematode Caenorhabditis elegans. Annu. Rev. Genet. 33, 399-422.

Mori, I., and Ohshima, Y. (1995). Neural regulation of thermotaxis in Caenorhabditis elegans. Nature 376, 344-348.

Morley, J. F., and Morimoto, R. I. (2004). Regulation of longevity in Caenorhabditis elegans by heat shock factor and molecular chaperones. Mol. Biol. Cell 15, 657-664.

Morris, J. Z., Tissenbaum, H. A., and Ruvkun, G. (1996). A phosphatidylinositol-3-OH kinase family member regulating longevity and diapause in Caenorhabditis elegans. Nature 382, 536-539.

Morrison, J. H., and Baxter, M. G. (2012). The ageing cortical synapse: hallmarks and implications for cognitive decline. Nat. Rev. Neurosci. 13, 240-250.

Mouravlev, A., Dunning, J., Young, D., and During, M. J. (2006). Somatic gene transfer of cAMP response element-binding protein attenuates memory impairment in aging rats. Proc. Natl. Acad. Sci. U.S.A. 103, 4705-4710.

Mulcahy, B., Holden-Dye, L., and O'Connor, V. (2012). Pharmacological assays reveal age-related changes in synaptic transmission at the Caenorhabditis elegans neuromuscular junction that are modified by reduced insulin signalling. J. Exp. Biol. (in press)

Murakami, H., Bessinger, K., Hellmann, J., and Murakami, S. (2005). Aging-dependent and -independent modulation of associative learning behavior by insulin/insulinlike growth factor-1 signal in Caenorhabditis elegans. J. Neurosci. 25, 10894-10904.

Murakami, S., and Murakami, H. (2005). The effects of aging and oxidative stress on learning behavior in C. elegans. Neurobiol. Aging 26, 899-905.

Murphy, C. T., Lee, S. J., and Kenyon, C. (2007). Tissue entrainment by feedback regulation of insulin gene expression in the endoderm of Caenorhabditis elegans. Proc. Natl. Acad. Sci. U.S.A. 104, 19046-19050.

Murphy, C. T., McCarroll, S. A., Bargmann, C. I., Fraser, A., Kamath, R. S., Ahringer, J., et al. (2003). Genes that act downstream of DAF-16 to influence the lifespan of Caenorhabditis elegans. Nature 424, 277-283.

Nakai, J., Ohkura, M., and Imoto, K. (2001). A high signal-to-noise $\mathrm{Ca}(2+)$ probe composed of a single green fluorescent protein. Nat. Biotechnol. 19, 137-141.

Niebur, E., and Erdos, P. (1991). Theory of the locomotion of nematodes: dynamics of undulatory progression on a surface. Biophys. J. 60, 1132-1146.

Nonet, M. L. (1999). Visualization of synaptic specializations in live C. elegans with synaptic vesicle proteinGFP fusions. J. Neurosci. Methods 89, 33-40.

Nuttley, W. M., Atkinson-Leadbeater, K. P., and Van Der Kooy, D. (2002). Serotonin mediates food-odor associative learning in the nematode Caenorhabditis elegans. Proc. Natl. Acad. Sci. U.S.A. 99, 12449-12454.

Oda, S., Tomioka, M., and Iino, Y. (2011). Neuronal plasticity regulated by the insulin-like signaling pathway underlies salt chemotaxis learning in Caenorhabditis elegans. J. Neurophysiol. 106, 301-308.

Ogg, S., Paradis, S., Gottlieb, S., Patterson, G. I., Lee, L., Tissenbaum, H. A., et al. (1997). The Fork head transcription factor DAF-16 transduces insulin-like metabolic and longevity signals in C. elegans. Nature 389, 994-999.

Pan, C. L., Peng, C. Y., Chen, C. H., and McIntire, S. (2011). Genetic analysis of age-dependent defects of the Caenorhabditis elegans touch receptor neurons. Proc. Natl. Acad. Sci. U.S.A. 108, 9274-9279.

Panowski, S. H., Wolff, S., Aguilaniu, H., Durieux, J., and Dillin, A. (2007). PHA-4/Foxa mediates dietrestriction-induced longevity of C. elegans. Nature 447, 550-555.

Paradis, S., Ailion, M., Toker, A., Thomas, J. H., and Ruvkun, G. (1999). A PDK1 homolog is necessary and sufficient to transduce AGE-1 PI3 kinase signals that regulate diapause in Caenorhabditis elegans. Genes Dev. 13, 1438-1452.

Paradis, S., and Ruvkun, G. (1998). Caenorhabditis elegans Akt/PKB transduces insulin receptor-like signals from AGE-1 PI3 kinase to the DAF-16 transcription factor. Genes Dev. 12, 2488-2498.
Pavlov, I. P. (1927). Conditioned Reflexes: An Investigation of the Physiological Activity of the Cerebral Cortex. Oxford: Oxford University Press.

Pereira, S., and van der Kooy, D. (2012). Two forms of learning following training to a single odorant in Caenorhabditis elegans AWC neurons. J. Neurosci. 32, 9035-9044.

Pierce, S. B., Costa, M., Wisotzkey, R., Devadhar, S., Homburger, S. A., Buchman, A. R., et al. (2001). Regulation of DAF-2 receptor signaling by human insulin and ins-1, a member of the unusually large and diverse C. elegans insulin gene family. Genes Dev. 15, 672-686.

Pierce-Shimomura, J. T., Morse, T. M., and Lockery, S. R. (1999). The fundamental role of pirouettes in Caenorhabditis elegans chemotaxis. J. Neurosci. 19, 9557-9569.

Porte, Y., Buhot, M. C., and Mons, N. (2008). Alteration of CREB phosphorylation and spatial memory deficits in aged 129T2/Sv mice. Neurobiol. Aging 29, 1533-1546.

Raizen, D. M., Lee, R. Y., and Avery, L. (1995). Interacting genes required for pharyngeal excitation by motor neuron MC in Caenorhabditis elegans. Genetics 141, 1365-1382.

Rand, J. B., and Russell, R. L. (1984). Choline acetyltransferasedeficient mutants of the nematode Caenorhabditis elegans. Genetics 106, 227-248.

Rankin, C. H., Beck, C. D., and Chiba, C. M. (1990). Caenorhabditis elegans: a new model system for the study of learning and memory. Behav. Brain Res. 37, 89-92.

Richmond, J. (2007). "Synaptic function," in WormBook, ed. The C. elegans Research Community (WormBook), doi/10.1895/ wormbook.1.69.1. Available at: http://www.wormbook.org

Richmond, J. E., Davis, W. S., and Jorgensen, E. M. (1999). UNC-13 is required for synaptic vesicle fusion in C. elegans. Nat. Neurosci. 2, 959-964.

Richmond, J. E., and Jorgensen, E. M. (1999). One GABA and two acetylcholine receptors function at the C. elegans neuromuscular junction. Nat. Neurosci. 2, 791-797.

Richter, C., Park, J. W., and Ames, B. N. (1988). Normal oxidative damage to mitochondrial and nuclearDNA is extensive. Proc. Natl. Acad. Sci. U.S.A. 85, 6465-6467.

Riddle, D. L., Swanson, M. M., and Albert, P. S. (1981). Interacting genes in nematode dauer larva formation. Nature 290, 668-671.
Saeki, S., Yamamoto, M., and Iino, Y. (2001). Plasticity of chemotaxis revealed by paired presentation of a chemoattractant and starvation in the nematode Caenorhabditis elegans. J. Exp. Biol. 204, 1757-1764.

Shirai, Y., Kouzuki, T., Kakefuda, K., Moriguchi, S., Oyagi, A., Horie, K., et al. (2010). Essential role of neuronenriched diacylglycerol kinase (DGK), DGKbeta in neurite spine formation, contributing to cognitive function. PLoS ONE 5, e11602. doi:10.1371/journal.pone.0011602

Silva, A. J., Kogan, J. H., Frankland, P. W., and Kida, S. (1998). CREB and memory. Annu. Rev. Neurosci. 21, 127-148.

Suh, Y., Atzmon, G., Cho, M. O., Hwang, D., Liu, B., Leahy, D. J., et al. (2008) Functionally significant insulin-like growth factor I receptor mutations in centenarians. Proc. Natl. Acad. Sci. U.S.A. 105, 3438-3442.

Sulston, J. E., and Horvitz, H. R. (1977). Post-embryonic cell lineages of the nematode, Caenorhabditis elegans. Dev. Biol. 56, 110-156.

Sulston, J. E., Schierenberg, E., White, J. G., and Thomson, J. N. (1983). The embryonic cell lineage of the nematode Caenorhabditis elegans. Dev. Biol. 100, 64-119.

Suzuki, H., Kerr, R., Bianchi, L., Frokjaer-Jensen, C., Slone, D., Xue, J., et al. (2003). In vivo imaging of C. elegans mechanosensory neurons demonstrates a specific role for the MEC-4 channel in the process of gentle touch sensation. Neuron 39, 1005-1017.

Tamura, T., Chiang, A. S., Ito, N., Liu, H. P., Horiuchi, J., Tully, T., et al. (2003). Aging specifically impairs amnesiacdependent memory in Drosophila. Neuron 40, 1003-1011.

Tank, E. M., Rodgers, K. E., and Kenyon, C. (2011). Spontaneous age-related neurite branching in Caenorhabditis elegans. J. Neurosci. 31, 9279-9288.

Tatar, M., Kopelman, A., Epstein, D., Tu, M. P., Yin, C. M., and Garofalo, R. S. (2001). A mutant Drosophila insulin receptor homolog that extends lifespan and impairs neuroendocrine function. Science 292, 107-110.

Thompson, R. F., and Spencer, W. A. (1966). Habituation: a model phenomenon for the study of neuronal substrates of behavior. Psychol. Rev. $73,16-43$.

Tian, L., Hires, S. A., Mao, T., Huber, D., Chiappe, M. E., Chalasani, S. H., et al. (2009). Imaging neural activity in worms, flies and mice with improved GCaMP calcium indicators. Nat. Methods 6, 875-881. 
Timbers, T. A., and Rankin, C. H. (2011). Tap withdrawal circuit interneurons require CREB for longterm habituation in Caenorhabditis elegans. Behav. Neurosci. 125, 560-566.

Tomioka, M., Adachi, T., Suzuki, H., Kunitomo, H., Schafer, W. R., and Iino, Y. (2006). The insulin/PI 3-kinase pathway regulates salt chemotaxis learning in Caenorhabditis elegans. Neuron 51, 613-625.

Torayama, I., Ishihara, T., and Katsura, I. (2007). Caenorhabditis elegans integrates the signals of butanone and food to enhance chemotaxis to butanone. J. Neurosci. 27, 741-750.

Toth, M. L., Melentijevic, I., Shah, L., Bhatia, A., Lu, K., Talwar, A., et al. (2012). Neurite sprouting and synapse deterioration in the aging Caenorhabditis elegans nervous system. J. Neurosci. 32, 8778-8790.

Troemel, E. R., Kimmel, B. E., and Bargmann, C. I. (1997). Reprogramming chemotaxis responses: sensory neurons define olfactory preferences in C. elegans. Cell 91, 161-169.

Tsalik, E. L., and Hobert, O. (2003). Functional mapping of neurons that control locomotory behavior in Caenorhabditis elegans. J. Neurobiol. 56, 178-197.

Tully, T., and Quinn, W. G. (1985). Classical conditioning and retention in normal and mutant Drosophila melanogaster. J. Comp. Physiol. A 157, 263-277.

Varshney, L. R., Chen, B. L., Paniagua, E., Hall, D. H., and Chklovskii, D. B. (2011). Structural properties of the Caenorhabditis elegans neuronal network. PLoS Comput. Biol. 7, el001066. doi:10.1371/journal.pcbi.1001066

Ward, S. (1973). Chemotaxis by the nematode Caenorhabditis elegans: identification of attractants and analysis of the response by use of mutants. Proc. Natl. Acad. Sci. U.S.A 70, 817-821.

Watson, J. B., and Raynor, R. (1920). Conditioned emotional responses. J. Exp. Psychol. 3, 1-14.

Weindruch, R. (1996). The retardation of aging by caloric restriction: studies in rodents and primates. Toxicol. Pathol. 24, 742-745.

Wenick, A. S., and Hobert, O. (2004). Genomic cis-regulatory architecture and trans-acting regulators of a single interneuron-specific gene battery in C. elegans. Dev. Cell 6 , 757-770.

White, J. G., Southgate, E., Thomson, J. N., and Brenner, S. (1986). The structure of the nervous system of the nematode Caenorhabditis elegans. Philos. Trans. $R$ Soc. Lond. B Biol. Sci. 314, 1-340.

Witte, A. V., Fobker, M., Gellner, R. Knecht, S., and Floel, A. (2009). Caloric restriction improves memory in elderly humans. Proc. Natl. Acad. Sci. U.S.A. 106, 1255-1260.

Wong, A., Boutis, P., and Hekimi, S. (1995). Mutations in the clk1 gene of Caenorhabditis elegans affect developmental and behavioral timing. Genetics 139, 1247-1259.

Wood, J. G., Rogina, B., Lavu, S., Howitz, K., Helfand, S. L., Tatar, M., et al. (2004). Sirtuin activators mimic caloric restriction and delay ageing in metazoans. Nature 430 , 686-689.

Zhang, Y., Lu, H., and Bargmann, C. I. (2005). Pathogenic bacteria induce aversive olfactory learning in Caenorhabditis elegans. Nature 438 , 179-184.

Zheng, Y., Brockie, P. J., Mellem, J. E., Madsen, D. M., and Maricq, A. V. (1999). Neuronal control of locomotion in C. elegans is modified by a dominant mutation in the GLR-1 ionotropic glutamate receptor. Neuron 24, 347-361.

Conflict of Interest Statement: The authors declare that the research was conducted in the absence of any commercial or financial relationships that could be construed as a potential conflict of interest.

Received: 31 July 2012; accepted: 05 November 2012; published online: 26 November 2012.

Citation: Stein GM and Murphy CT (2012) The intersection of aging, longevity pathways, and learning and memory in C. elegans. Front. Gene. 3:259. doi: 10.3389/fgene.2012.00259

This article was submitted to Frontiers in Genetics of Aging, a specialty of Frontiers in Genetics.

Copyright (c) 2012 Stein and Murphy. This is an open-access article distributed under the terms of the Creative Commons Attribution License, which permits use, distribution and reproduction in other forums, provided the original authors and source are credited and subject to any copyright notices concerning any third-party graphics etc. 